\title{
Dancing with the Daunting: An Analysis of the Challenges in Dating and Maintaining Heterosexual Dyadic Relationships in Older Adulthood
}

\author{
Elaine Tran ${ }^{1}$
}

\begin{abstract}
The purpose of this paper is to identify and examine the challenges and difficulties associated in the process of dating for older heterosexual adults in dyadic relationships. A number of unique barriers are explored, including particular attitudes towards aging which shaped older adults' self-presentation in online dating as well as characteristics older adults identified in prospective partners; barriers to dating due to the aging process, which manifested into smaller networks of social support; gender imbalance; and expressions of sexuality and intimacy. Moreover, gendered differences between men and women were also discussed, broadening into difference between presentation in online dating as well as relationship attitudes and outlook. Finally, some gaps within previous literature and research were presented in an attempt to promote more diverse and inclusive research on older adults, dating, and intimate romantic relationships.
\end{abstract}

\section{Dedication}

For much of my life, my dad has been a source of admiration, encouragement, and inspiration. As my dad has been divorced since his early 50s, for several years, I have watched him relentlessly work to care and provide for my brother and myself; struggle, at times, with raising two children as a single father; and more recently, navigate dating as an older adult. As the subject of my paper was inspired partly by my dad, I would like to dedicate my paper to him and acknowledge his perseverance and hopefulness in navigating the world of dating as an older adult. I remain hopeful for my dad, and many older adults all over the world who seek love head on, despite how daunting it can be.

\footnotetext{
${ }^{1}$ MacEwan University
} 
To commence, please keep the following quote from Betty Friedan in mind as an opportunity for reflection: "Aging is not lost youth, but a new stage of opportunity and strength" (Friedan, n.d.).

\section{Introduction}

The dream of finding a soulmate, the love of one's life, or simply the "one" is a ubiquitous desire in society. Whether in books, film, television; on billboards; or even on the streets, one can easily find a myriad of representations of intimate romantic relationships in everyday life. Today, perhaps more than ever, dating is made an even more ubiquitous concept due to the multitude of ways in which one is able to meet others. The search is no longer restricted to in-person meetings, nor classified ads in newspapers; rather, the rise of the internet and emergence of dating apps have opened a whole new domain in the world of dating. Due to the historical standards set out by society coupled with the omnipresence of intimate romantic relationships, one can observe why people aspire to find romantic companionship. Despite the pervasive representations of intimate romantic relationships, finding and maintaining a relationship with a partner is not as easy as it seems to be represented. Although the end result can be rewarding, the process can be tedious as well as challenging and difficult to navigate. The journey of searching for a prospective partner, moving into chatting and meeting with them, and finally forming a relationship is a long, and unguaranteed process. Rather, the process can be repetitive and is repeated over and over again until one is able to find a suitable match.

As one grows older, this undertaking becomes even more daunting with a different set of hurdles to overcome. Much of the scholarship on dating and intimate romantic relationships has focused on people of a younger generation in contrast to older adults in society. However, as the population of older adults in Canada continues to grow, research should shift to account for the changes in the lives of older adults, including navigating dating and intimate romantic relationships. Currently, as of July 1, 2020, Statistics Canada (2020) has documented 6,835,866 Canadians aged 65 and older (Key indicators, para. 1). Yet, it is estimated that this number will rise to 9.5 million, where adults aged 65 and older will account for 23 percent of Canadians by the year 2030 (Government of Canada, Profile of seniors in Canada, para. 2). As a young person who has navigated the process of dating myself and whose experience is represented in research and scholarship, I can understand how challenging and difficult it can be; but I could not imagine the challenges and difficulties posed for older adults. I hypothesize that older adults face additional unique challenges in dating, which complicates and differentiates some of their experiences in comparison to younger generations. In particular, by virtue of being older adults, they are faced with challenges surrounding self-presentation due to the negative perception of aging perpetuated by society and reinforced in media (Gewirtz-Meydan \& Ayalon, 2018, p. 486). Therefore, the aim of this paper is to highlight the experiences of the growing population of older adults in seeking and maintaining intimate romantic relationships, with the hope of promoting further research and scholarship on the subject. To commence my analysis, I define the term "older adult" and its usage within the context of my paper. Following this, I move into 
examining the unique challenges and difficulties for older adults in the dating process. The first barrier that will be discussed is self-presentation and the presentation of prospective partners in mate-seeking for older adults in the world of online dating. Secondly, barriers to dating due to the aging process will be revealed, namely smaller networks of support; gender imbalance; and expressions of sexuality and intimacy. Thirdly, I will discuss some gendered differences between men and women. Lastly, I will conclude by examining some limitations and gaps within research and scholarship. As a clarification, this paper will highlight the challenges and experiences of heterosexual older adults in dyadic (single partner or non-polyamorous) intimate romantic relationships. Therefore, the experiences of older adults in the LGBTQ+ community as well as adults interested or participatory in polyamorous relationships will not be discussed or explored in this paper.

\section{Not Quite Seniors Citizens: Defining Older Adulthood}

As defined by the Government of Canada (2020), Canadians aged 65 and older are categorized as seniors (Profile of seniors in Canada, para. 2). Although the categorization of adults aged 65 and older as seniors provides further insight into the classification of a subset of older adults, the term "senior" does not accurately, nor wholly encompass older adults as a distinct population. Moreover, the Government of Canada has not created a true definition for older adults, which has left a gap that is open to interpretation. In a similar fashion, through my own exploration of a broad body of scholarship on the subject of older adults, dating, and intimate romantic relationships, researchers and scholars were inconsistent in their definition of older adults as well. Therefore, within previous scholarship, perhaps in part due to lack of a true definition for older adults, the age range for older adults varied from study to study. As such, in the literature, the age range of the sample populations in each of the studies varied from individuals aged 50 and older, to 55 and older, and 65 and older, to disclose a few. For the purpose of this paper, older adults will be defined as individuals aged 50 and older. The age of 50 was determined to be the most accurate and best encompassing term because it was the most prevalent and lowest age represented in the literature to classify older adults. Therefore, to establish context for my paper, and for both consistency and ease, the term "older adult(s)" will refer to individuals beginning at the age of 50 and older.

\section{Self-Presentation and Ideal Partner Presentation: How Do Older Adults Want Others to See Them and What Do Adults Desire in the Visual Presentation of Other Older Adults?}

In his sociological book, The Presentation of Self in Everyday Life, Goffman (1959) uses the representation of theatre as a tool to conceptualize human interaction within everyday life. In addition, Goffman also uses the representation of a mask to conceptualize the self that one presents to others in everyday life. Goffman's ideas surrounding the presentation and representation of self in everyday human interactions can be used as a tool to better understand how and why older adults present themselves in dating within this section in particular. More 
specifically, this section will discuss self-presentation in online dating; however, it can be inferred that older adults' self-presentation, in some ways, can be adapted offline in a similar fashion. In my literature search, much of the previous scholarship focused on older adults' selfpresentation in the world of online dating, limiting my following analysis to older adults' selfpresentation within the infancy stage of dating, even before they meet others. However, despite the lack of research on older adults' self-presentation on in-person dates, the previous literature on online dating will nonetheless be useful in understanding how older adults want to be seen and what they see in other older adults in the dating process.

In speaking about self-presentation, Goffman (1959) proclaims, "In a sense, and in so far as this mask represents the conception we have formed of ourselves - the role we are striving to live up to - this mask is our truer self, the self we would like to be" (p. 48). In essence, Goffman asserts that the "mask" - or self - presented to others is an idealized version of us - a version to which we aspire. As previously mentioned, Goffman's conceptualization can be used as a tool to connect older adults' self-presentation in online dating. In the world of dating, everyone - not just older adults - likely aims to present an attractive version of themselves. In addition, aging in the media has not been presented positively, and "the mass media have had an overall negative effect on society's attitude toward aging as most people portrayed in the media are young and virile" (Vickers, 2007, as cited in Gewirtz-Meydan \& Ayalon, 2018, p. 486). As such, both of these pieces of information should be considered in examining older adults' self-presentation in both online and offline dating.

For older adults, the considerations that need to be made in their self-presentation in dating profiles is a unique challenge. McWilliams and Barrett (2014) reinforce that older adults are aware of the self-presentation of their age in online dating and identify age as a concept of concern for many older adults (p. 416). More specifically, older adults are encouraged to present themselves as younger or more youthful looking because many other older adults are attracted to and interested in prospective partners who are deemed "'not old"' (McWilliams \& Barrett, 2014, p. 416). Consequently, by presenting themselves in this manner, older adults combine the conception of Goffman's truer self in addition to the ideals imposed by media and society on aging in the presentation of themselves in the dating process. In addition, McWilliams and Barrett (2014) further reveal that the misrepresentation of one's age as less than one's true chronological age is another theme for older adults in the construction of their online dating profiles (p. 416). Accordingly, the presentation of oneself as younger also aligns with the selfconceptualization and self-understanding of older adults because "[a]s adults age, they report feeling increasingly younger than their actual chronological age (Kleinspehn-Ammerlahn, Kotter-Grühn, \& Smith, 2008, as cited in McWilliams \& Barrett, 2014, p. 416). Thus, older adults' misrepresentation of their age in online dating is another method not only to present the ideal of youthfulness to others, but to reinforce that narrative within themselves as well.

Furthermore, in their study, Gewirtz-Meydan and Ayalon (2018) found that "signs of aging, such as wrinkles, gray hair, loss of hair, or eyeglasses were absent from most pictures, [and] [f] eatures indicating physical difficulties, such as a cane, a walker, or even a wheelchair were not present at all" (p. 496). As well, "old men and women who did not fit these [media and societal reinforced] ideals and did not represent successful and youthful aging were simply not found on the sites" (Gewirtz-Meydan \& Ayalon, 2018, p. 496). Continually, it can be concluded 
that older adults' self-presentation focused on societal ideals of attractiveness in the dating process in addition to media reinforced ideals of aging and youth. As such, from the previous literature, it can be ascertained that many older adults' self-presentation is in alignment with what they are looking for in a prospective partner (not accounting for gendered differences) coincidentally. All of this reveals the challenges and difficulties older adults are tasked with in the dating process, and more specifically within the world of online dating, but which the younger generation does not have to consider. Older adults' self-presentation reinforces an idealized conceptualization of aging perpetuated not only by society, but by older adults as well. As such, older adults reinforce ageism narratives present within media and society on others yet try to prevent the same narratives from being imposed onto them, which creates a paradox. Therefore, a unique challenge or complication burdened on older adults in both self-presentation as well as in ideal partner presentation is the perpetuation of ageism, as older adults are tasked with concealing visible signs of aging or disability in addition to seeking prospective partners who are devoid of such elements.

\section{Barriers to Dating Due to the Aging Process}

As previously mentioned, the process of dating can be fraught with challenges and difficulties at any age; however, unlike younger generations, older adults, who are farther along in the aging process are presented with a number of unique barriers presented to the dating process due to their age. More specifically, in this section, three barriers to the dating process posed by the aging process will be explored, namely smaller social networks of support; gender imbalance; and the expression of sexuality.

\section{A Lonely Road: Smaller Social Networks of Support}

Building and maintaining social networks of support is a dynamic process that fluctuates with age. In childhood, adolescence, and early teenage years, people can build relationships by attending school and engaging in extracurricular activities. Within one's youth, social functions, such as outings to bars, or parties can also further influence one's social network, either building or maintaining it through constant connection with others. In early adulthood, one's journey into post-secondary and entry into the workforce can continue to build and maintain one's social networks of support. However, as one ages, these experiences can fade and fall into memory as one is tasked with planning for retirement or in retirement; attending to health needs, or a loved one's health needs; experience relocation to long-term care, among other factors. For older adults, it can be more difficult to cultivate relationships, and dating can be used to prevent the burden of loneliness as one grows older and older in an attempt to forge new connections and seek companionship (Stevens, 2002). Carr (2004) found that men's ties to social networks of support dictated their interest in dating. More specifically, men with a lower level of social support from a network of friends were more interested in dating than men with higher levels of social support from a network of friends. In addition, men with lower levels of ties to social networks of sup- 
port were also more interested in remarriage. Therefore, it can be suggested that dating can be a way for older men to maintain social support through life-long companionship that they currently lack without a long-term partner. In a similar fashion, "[f]or some older adults, forming a new partnership that provides close ties is preferable to relying on their adult children for social support and interaction" (Stevens, 2002, as cited in Brown \& Shinohara, p. 1195). Both of the above pieces of information suggest that intimate romantic relationships could replace support from friends and children; therefore, it can be argued that intimate relationships formed through dating are one of the most important, if not the most important, forms of social support for older adults. The individuals that comprise our social networks of support contribute to integral and unique relationships. For older adults, whose social networks of support can be strained or weakened with age, intimate romantic relationships are then a critical partnership within one's social network of support, much like any other.

\section{More Guys than Gals: Gender Imbalance}

According to Bushnik, Tjepkema, and Martel (2018), "life expectancy at birth in Canada has risen substantially to 79.8 years for males, and 83.9 years for females" (para. 1). This information confirms the notion that life expectancy differs between men and women. As such, a gender imbalance can form due to a larger proportion of women lasting in old age in comparison to men, which can come to pose a barrier to dating for older men and women alike. In their study, using a national sample of older adults from age 57 to 85, Brown and Shinohara (2013) found that older men accounted for nearly two third of daters. Taking this into account, for older women, that can contribute to a more difficult time in dating and seeking intimate romantic relationships due to the lack of available older men, (McIntosh et al, 2011, as cited in Wada, Mortenson, \& Clarke, 2016) given women's higher life expectancy rate. Moreover, for older men, despite there being a larger pool of available older women, it has been noted that older women are "more selective than their male counterparts regarding the characteristics of a potential partner (McIntosh, et al., 2011, as cited in Wada, Mortenson, \& Clarke, 2016, p. 480). Therefore, although there is a smaller proportion of men to choose from, that does not mean that there will necessarily be more compatible nor desirable men, especially due to older women's increased selectivity. Overall, the prevalence of a gender imbalance due to the aging process presents complications unique to the population of older men and women, and can come to influence the ease in which they are able to date and pursue intimate romantic relationships in older adulthood.

\section{“Ask your Doctor”: Expressions of Sexuality and Intimacy}

As previously mentioned, aging and old age have been negatively represented in media, which has contributed to negative attitudes towards aging (Vickers, 2007, as cited in GewirtzMeydan \& Ayalon, 2018). In the media, the aging process is represented by illustrations of health and wellness in decline, with health complications and problems emerging in their place. 
For example, on television, there are multiple advertisements targeted at older men with erectile dysfunction in an attempt to provide a remedy for their temporary sexlessness. By and large, in society, older adults are represented as asexual or sexless. However, research suggests this assertion to be mythological. In examining adults over 65, Adams, Oye, and Parker (2003) identified that "myths are driven, in part, by a parallel force to maintain youth, or at least its illusion, at all costs (e.g., cosmetics, hair dye, plastic surgery, anti-ageing medicines, etc.) and that success and beauty at strictly a commodity for the young (p. 406). Therefore, the myths and negative representations of older adults are due to the preservation and value of youth and can further propagate ageism in society. In contrast to what is presented in the media, "when older adults give up their sexuality, it is primarily due to social and psychological causes rather than biological and physical causes, which can usually be remedied (Hillman, 2000, as cited in Adams, Oye, \& Parker, 2003, p. 407). As such, sexlessness is associated with broader invisible factors, rather than physical or visible ones, as suggested within media and society. In a study with 30 "Polish men and women aged 65 and over", it was discovered that there are multiple meanings of sex as articulated by older men and women (Gore-Gorszewska, 2020, p. 4). Most notably, Gore-Gorszewska's (2020) study concluded that older men and women reconceptualized their view of sex as "physical intimacy in various forms (fondling, kissing, touching, etc." (p. 8). Therefore, for some older adults, physical non-sexual intimacy has become synonymous with sexual activity. Moreover, adults in their study viewed "penetrative intercourse as inessential" (Gore-Gorszewska, 2020, p. 9). Rather, for older men and women sex was conceptualized as the following: 1) "emotional intimacy"; 2) "sex [as] inseparable from the bond and mutual understanding between partners"; and 3) "respect between partners" (GoreGorszewska, 2020, pp. 10-11). As such, for older adults, sexuality has been reconceptualized and redefined to encompass more emotionally intimate activities, and not necessarily sexually intimate ones. As previously mentioned, the negative representations of aging perpetuated in both media and society can influence the way in which sexuality is viewed in connection with older adults. Though, it is interesting to note that although these myths and narratives continue to exist, there are ways in which older men and women are able to continue to implement sexuality into their lives. More specifically, it is interesting to observe how older men and women have redefined the boundaries of sexuality for themselves.

\section{Gendered Differences between Men and Women}

Much like anything else in life, there are a number of differences between men and women in the world of dating. In this section, desires and ideal surrounding self-presentation in online dating profiles will be discussed in addition to older men and women's attitudes toward intimate romantic relationships. In the creation of online dating profiles, for both men and women, the demands, desires, and ideals imposed on self-presentation were similar. (GewirtzMeydan \& Ayalon, 2018, p. 486). However, there are gendered differences for men and women due to "the intersection of gender and age inequality [which] results in different experiences" (Gewirtz-Meydan \& Ayalon, 2018, p. 486). In their online dating profiles, men and women present themselves as aligned with the standards imposed by binary constructs of "heterosexual 
femininity and masculinity" (West \& Zimmerman, 1987, as cited in McWilliams \& Barrett, 2014, p. 416). Additionally, throughout the self-presentation process, older men and women considered both binary constructs of "heterosexual femininity and masculinity" (West \& Zimmerman, 1987, as cited in McWilliams \& Barrett, 2014, p. 416) in tandem with youthfulness to create an attractive profile. As such, for women, youthful and feminine profiles were composed around visual representation or looks; while for men, youthful and masculine profiles were composed around gainful employment or financial stability (McWilliams \& Barrett, 2014, p. 416). Therefore, for both men and women alike, attractiveness and desirability were rooted in the binary understanding of gender; however, these characteristics differ in manifestation for men and women due to the binary. As a result, there are unique challenges posed for older adults, but a gendered divide is further revealed in the self-presentation process, which yields different experiences and results for men and women.

In regard to attitudes on intimate romantic relationships, older men and women varied quite significantly in their outlook. McWilliams and Barrett (2014) identified that older men were interested in sealing or validating intimate relationships through marriage. In contrast, older women simply preferred companionship rather than marriage (McWilliams \& Barrett, 2014). Therefore, between older men and women, men are more likely to desire romantic monogamous relationships than women who prefer friendly companionship. Furthermore, Jacobsen, Kent, Lee and Mather (2011) found that "[a]mong the population ages 65 and older, about three-quarters of men but less than half (44 percent) of women were married in 2010" (p. 4). In part, the divide in relationship outlook of older men and women may be able to provide some insight as to the imbalance between marriage and older adults. In addition, McWilliams and Barrett (2014) noted that autonomy was a factor in women's disinterest a long-term commitment, such as marriage. In addition, Dickson et. al (2005) concluded that women's interest in companionship rather than marriage can be attributed to women's fears of being constrained to the role of caregiver as their prospective partner ages. As such, it can be inferenced that women prioritize long-term personal independence and freedom in contrast to long-term interpersonal partnerships. Moreover, for some women, dating is viewed "as a social activity that provides a unique form of companionship not achieved through friendships with other women (Davidson, 2001; Watson \& Stelle, n.d., as cited in Brown \& Shinohara, 2013, p. 1195). Therefore, the gender imbalance between and women, due to age, also restricts their personal friendships. As a result, older women may combat this challenge by diversifying their friendships through dating.

All in all, there are a multitude of gendered differences between older men and women in the dating process. These differences manifest uniquely, such as through visual perception or presentation or within relationship attitudes and outlook. Regardless of the differences between older men and women, these differences affect and are driven by older adults as a whole because of their age in contrast to younger generations.

\section{Gaps in Literature}

The term "older adult" was defined in order to narrow and specify the scope of the paper. Previously, it was revealed that the Government of Canada does not possess a true definition for 
the population of older adults in Canada; rather, there only exists a term for a small subset of older adults, namely seniors. Therefore, one of the most prominent gaps was a lack of consistency between studies in defining the age at which older adulthood begins. Rather, older adulthood ranged from aged 50, 55, to 65 and older. As such, perhaps older adulthood needs to be better defined by an international body, or national governments in order to promote consistency and continuity between researchers and within studies. The question which arises from all of this is: who can be classified as an older adult?

Additionally, much of the scholarship did not disclose factors for race or ethnicity. Future scholarship should identify the distinctions between race and ethnicities for older adults in order to determine cultural nuances which likely exist in the dating process and within romantic relationships. Furthermore, the exploration of culture and race deviations would provide further insight into how older adults can differ or be similar in dating attitudes, practices, and results, among other considerations. A deeper analysis using an intersectional framework should be implemented in future studies in order to tap into an understudied population of older adults, and their intersecting identities (especially older adults who would not be racialized as white). By promoting the idea of more ethnically and racially informed studies, it would simultaneously broaden yet specify the literature which exists on older adults, dating, and intimate romantic relationships.

Throughout my research, much of the literature and previous scholarship on older adults and intimae romantic relationships focused on heterosexual adults, in addition to adults who previously were in or were pursuing dyadic relationships. Although there were some studies which focused on LGBTQ+ adults alone, or in conjunction with heterosexual adults, they were mainly contextualized within dyadic relationships. Rarely did I encounter papers on the subject of polyamory. Because we live in a heteronormative society, it is generally understood that much research on intimate romantic relationships has historically focused on heterosexual unions as well as dyadic unions; however, further research on same-sex and polyamorous unions should be explored in order to promote diverse research on older adults.

\section{Conclusion}

Dating and forming intimate romantic relationships is a part of life, which can be as joyful and rewarding as it is challenging and difficult. In this paper, the unique challenges and difficulties for older adults in the dating process were explored and shed light onto the barriers to dating for older men and women. Dating, as an older adult, has posed unique challenges and can be more daunting, especially when the pool to find others your age is so narrow, and it can be easy to feel alone throughout the process. A number of unique barriers have been explored, including particular attitudes towards aging which shaped older adults' self-presentation in online dating as well as characteristics older adults identified in prospective partners; barriers to dating due to the aging process, which manifested into smaller networks of social support; gender imbalance; and expressions of sexuality and intimacy. Moreover, gendered differences between men and women were also discussed, resulting in both different expectations and effects 
for older adults. Lastly, limitations and gaps within research were presented in an attempt to promote more diverse and inclusive research on the subject of dating in older adulthood. In closing, the dating process is one that has been navigated by many people all over the world throughout life, and the experience of each individual person alone is diverse and fascinating, including for older men and women whose experiences are unique. 


\section{References}

Adams, M., Oye, J., \& Parker, T. (2003). Sexuality of older adults and the internet: From sex education to cybersex. Sexual and Relationship Therapy, 18(3), 405-415. https://doi.org/10.1080/1468199031000153991

Brown, S.L., \& Shinohara, S.K. (2013). Dating relationships in older adulthood: A national portrait. Journal of Marriage and Family, 75(5), 1194-1202. https://doi.org/10.1111/jomf.12065

Bulcroft, R.A. \& Bulcroft, K.A. (1991). The nature and functions of dating in later life. Research on Aging, 13(2), 244-260. https://doi.org/10.1177/0164027591132007

Bushnik, T., Tjepkema, M., \& Martel, L. (2018, April 18). Health reports: Health-adjusted life expectancy in Canada. https://www150.statcan.gc.ca/n1/pub/82-003x/2018004/article/54950-eng.htm

Carr, D. (2004). The desire to date and remarry among older widows and widowers. Journal of Marriage and Family, 66(4), 1051-1068. https://doi.org/10.1111/j.00222445.2004.00078.x

Friedan, B. (n.d.). Betty Friedan quotes. BrainyQuote. https://www.brainyquote.com/quotes/betty_friedan_383994\#: :text=Betty\%20Friedan\%2 0Quotes\&text=Please $\% 20$ enable $\% 20$ Javascript,Aging\%20is\%20not $\% 201$ ost $\% 20$ youth $\% 20$ but,stage $\% 20$ of $\% 20$ opportunity $\% 20$ and $\% 20$ s trength.

Gewirtz-Meydan, A., \& Ayalon, L. (2018). Forever young: Visual representations of gender and age in online dating sites for older adults. Journal of Women and Aging, 30(6), 484-502. https://doi.org/10.1080/08952841.2017.1330586

Goffman, E. (1959). The presentation of self in everyday life. In C. Calhoun, J. Gertis, J. Moody, S. Pfaff, \& I. Virk (Eds.), Contemporary Sociological Theory, 3rd edition (pp. 46-61). John Wiley \& Sons Canada Ltd.

Gore-Gorszewska, G. (2020). "What do you mean by sex?" A qualitative analysis of traditional versus evolved meanings of sexual activity among older women and men. The Journal of Sex Research, 1-16. https://doi.org/10.1080/00224499.2020.1798333

Government of Canada. (2019, March 25). Government of Canada-Action for seniors report. https://www.canada.ca/en/employment-social-development/programs/seniors-actionreport.html

Jacobsen, L.A., Kent, M., Lee, M., \& Mather, M. (2011). America’s aging population. Population Bulletin, 66(1), 1-18. http://content.ebscohost.com/ContentServer.asp?EbscoContent=dGJyMNHX8kSeprM4w tvhOLCmsEiep7RSsKu4S7WWxWXS\&ContentCustomer=dGJyMPGqt0uyrLVRuePfge $\mathrm{yx} 43 \mathrm{zx} 1 \% 2 \mathrm{~B} 6 \mathrm{~B} \& \mathrm{~T}=\mathrm{P} \& \mathrm{P}=\mathrm{AN} \& \mathrm{~S}=\mathrm{R} \& \mathrm{D}=$ her $\& \mathrm{~K}=59924804$

McWilliams, S., \& Barrett, A.E. (2014). Online dating in middle and later life: Gendered expectations and experiences. Journal of Family Issues, 35(4), 411-436. https://doi.org/10.1177/0192513X12468437 
Statistics Canada. (2020, October 5). Seniors and aging statistics: Key indicators, number of persons aged 65 years and older. https://www.statcan.gc.ca/eng/subjectsstart/seniors_and_aging

Stevens, N. (2002). Re-engaging: New partnerships in late-life widowhood. Ageing International, 27, 27-42. https://doi.org/10.1007/s12126-002-1013-1

Thomeer, M.B., Umberson, D., \& Reczek, C. (2020). The gender-as-relational approach for theorizing about romantic relationships of sexual and gender minority mid-to later-life adults. Journal of Family \& Theory Review 12(2), 220-238, https://doi.org/10.1111/jftr.12368

Vandeweerd, C., Myers, J., Coulter, M., Yalcin, A., \& Corvin, J. (2016). Positives and negatives of online dating according to women 50+. Journal of Women and Aging, 28(3), 259-270. https://doi.org/10.1080/08952841.2015.1137435

Wada, M., Moretenson, W.B., \& Clarke, L.H. (2016). Older adults' online dating profiles and successful aging. Canadian Journal on Aging, 35(4), 479-490. https://doi.org/10.1017/S0714980816000507

Watson, W.K., Stelle, C., \& Bell, N. (2017). Older women in new romantic relationships: Understanding the meaning and importance of sex in later life. The International Journal of Aging and Human Development, 85(1), 33-43. https://doi.org/10.1177/0091415016680067 